\section{Alan Mitchell}

is Chairman of the Buyer Centric Commerce Forum and a founder of Ctrl-Shift Ltd. Also serves the Berkman Center's Project VRM Steering Committee.

\section{Iain Henderson}

is CEO of MyDex (www.mydex. org), a Community Interest Company focused on personal information management. Also serves the Berkman Center's Project VRM Steering Committee.

\section{Doc Searls}

is a Fellow with the Berkman Center for Internet and Society at Harvard University. Doc Searls leads the Berkman Center's Project VRM Steering Committee.

Keywords: VRM (vendor relationship management), CRM, ROI, response rates, database management, relevance, consumer empowerment, buyer-centricity, permission marketing, privacy, opt-in

\section{Opinion Piece}

\section{Reinventing direct marketing - with VRM inside}

\author{
Alan Mitchell, lain Henderson and Doc Searls \\ Received: 1 May 2008
}

\begin{abstract}
Direct marketing is now faced with endemic crisis. Toxic ingredients of this crisis include rising consumer concerns about privacy and data protection, growing hostility and resistance to unwanted messaging, rising costs, falling returns, increasing concerns about environmental impact, and intensifying regulatory scrutiny and restrictions. Three core characteristics of direct marketing are responsible for these problems; (1) Data management: all responsibility for data management (collection, storage, analysis, usage, etc) lies with the seller; (2) Information flows are almost wholly 'top down' from sellers to buyers in the form of selling messages; (3) Metrics: success is defined in sellercentric terms - costs versus benefits to the seller. By empowering individuals to collect, store and share rich, up-to-date personal data with suppliers, vendor relationship management (VRM) offers a way through direct marketing's current impasse. To realise the new win-wins made possible by VRM, the industry needs to start adjusting now.
\end{abstract}

Journal of Direct, Data and Digital Marketing Practice (2008) 10, 3-15. doi:10.1057/dddmp.2008.24

Computer users know that sinking feeling when a 'hard re-set' is required. Typically, this happens when a system gets its inner workings so tied up in knots that the only way to fix it is to wipe the slate clean and start again.

Direct marketing has reached such a situation. Designed for a world where organisations were the sole drivers of the direct marketing process, it cannot cope with an emerging environment where individuals are much more able to match their requirements to the products and services that meet their needs. To survive and prosper, direct marketing needs to align itself with new realities. It needs a hard re-set.

\section{A maturing trend}

121 Abbeville Road

London SW4 9JL

UK

Tel: +440207622 4987

E-mail: ASMitchell@aol.com
Starting with the PC back in the early 1980s and accelerating through new developments such as broadband internet, individuals are becoming increasingly able to do all the things organisations do with 


\section{Direct marketing's crisis}

data: collect, store, analyse and share with others. Now, technology trends that have been under way for decades are crystallising under the banner of 'vendor relationship management' (VRM).

VRM is a set of tools, technologies, services and new business models that help individuals

- build and use their own personal data stores

- choose who to share which portions of these data with, on what terms, for what purposes

- send messages to suppliers and/or the market

- put customers in a much better to position to manage their relationships with vendors (existing and potential suppliers).

In the past, relationship management was mostly a one-way affair. With VRM it will be two-way, with significant benefits for both parties.

VRM is arriving just at the right time for the direct marketing industry, which is now in a state of endemic crisis. Toxic ingredients of this crisis include rising consumer concerns about privacy and data protection, growing hostility and resistance to unwanted messaging, falling returns, rising costs, increasing concerns about environmental impact, and intensifying regulatory scrutiny and restrictions. But how can VRM help?

\section{Climbing to the moon}

Direct marketing's single most compelling USP is 'relevance'. If a buyer and a seller can connect about the right thing at the right time via the right channel, a powerful win-win is unleashed. Both sides can reap significant value by using and exchanging the right information.

Unfortunately, these win-wins are massively undermined and sometimes obliterated by the industry's seller-centric history and operation.

The industry's current modus operandi goes something like this. Organisations harvest as much data as they can about customers primarily transaction and behavioural data supplemented by data from other sources such as purchased lists, market research and so on. They 'mine' and analyse these data, looking for trends and patterns. Then they use the insights generated to create profiles of likely customers, distinguish highly profitable customers from less profitable ones, and identify which customers are most likely to be open to up-selling, cross-selling or (perhaps) defection. They then target these customers with appropriate messages, designed to get them to respond in some way, such as take up an offer.

This set-up displays a number of core characteristics.

- The organisation bears all the responsibility for data capture, storage, cleansing, analysis, messaging, etc.

- Almost all of these data are 'harvested' from customer actions, not volunteered. 


\section{Most metrics tell only half the story}

\section{Consumers don't value direct marketing}

- Once it is harvested it is treated as an organisational and not a personal asset; it is there to be used by the organisation in any way it sees fit, such as selling it on to third parties (so long as it stays within the law or hides behind obscure terms and conditions).

- Success is measured exclusively by seller-centric criteria: how the initiative improves the seller's ROI, sales, margins, market share, etc. The costs or benefits incurred by customers remain unmeasured. Even when some attention is paid to "customer satisfaction', it is couched in terms of the impact on the organisation, for example, 'will this customer recommend us to others...'.

- Many different organisations are all collecting their own data separately, and their ability to harvest data is constrained by the content, nature and frequency of their interactions with their customers. As a result, (1) there is massive duplication of effort and (2) no single organisation has a full picture of its customers' behaviours, preferences, transactions, etc.

- Because most of these data are harvested indirectly rather than volunteered directly, it misses dimensions of information that only the customer knows, that is, 'why I bought that XXX', 'I am planning to buy a car/mortgage/new kitchen/skiing holiday over the next three months' or 'my circumstances/priorities/preferences have now changed'.

- Because direct marketing treats customer data as an organisational asset and measures success solely from the organisations' point of view, consumers do not see it as something that benefits them. Therefore, they see no reason to invest time, effort or information helping direct marketers achieve their goals.

- Because direct marketers' data are never complete (out-of-date, a partial view of customers, lack of access to volunteered data), they are always looking for new ways of accessing more relevant personal data. This is increasingly counterproductive, however, because it is often seen as an intrusive invasion of privacy.

- As a result, despite its best intentions, most direct marketing today is based on guesswork - guesswork informed by a little bit of data, but guesswork nevertheless.

This combination of factors explains and defines the industry's current obsessions and limitations. If marketers mailed or e-mailed every individual in the land with an offer, they would be bound to generate a certain number of responses. If they could then eliminate 10,20 or 30 per cent of non-responders from this mailing, then their costs would go down and their response rate would go up. This is the central agenda of data-driven 'insight' today: to reduce the wastage generated by guesswork.

This is like trying to reach the moon by climbing a tree. Taking this approach you can indeed get a little closer to your goal. But it will never get you to where you want to be. There is a structural flaw and it cannot be resolved within the existing framework. 


\section{VRM places information management tools in the hands of the individual}

From within this structure - built around organisation-managed customer data - current approaches to customer data are valid, sensible and essential: the higher you can climb your tree (perhaps you can build a skyscraper!), the closer you get to the moon and the more you reduce the waste inherent in guesswork. But looked at from the point of view of the moon itself, the claimed ability to deliver relevance is bogus.

Only the customer knows what he or she is interested in and when he or she is interested in it. Only the customer can generate a genuine single customer view. Only the customer can generate true insight and truly relevant messaging. This is the starting point of VRM, which enables customers to say to suppliers, 'This is me. Here I am. This is what I want to buy right now, next week, next summer...'.

In the past (ie before the internet) direct marketing had little choice but to operate in an environment where organisations alone could organise data about customers and put it to use. For years after the internet came along, it was seen by suppliers as the source of new marketing opportunities that augmented old approaches while providing new tools for targeting, placement and so on.

But the internet equips the demand as well as the supply side, and it equips the demand side with much more than increased choice alone. In the long run, customers will have tools for shopping and buying that match or exceed the power of those used for marketing and selling, and this 'long run' is arriving much faster than many marketers expected.

\section{The power of VRM}

VRM is not one single 'application' or system. It is not a Siebel or Salesforce.com 2.0, although, inevitably, those kinds of systems will come to embrace it. Instead, VRM is a collection of many different tools, technologies and services - developed by different providers, for different specialised purposes — that help individuals manage their personal data better for their own purposes.

VRM covers a wide range of functions, including building personal databases, communicating with organisations/markets, personal data analytics (eg what am I spending my money on, who with, etc) and improved decision making (see http://www.rightsideup.net/ buyercentricbasics2.htm for some examples). Separately and together, these new functions will give customers better ways to shop, buy and interact with their suppliers (Table 1).

From the marketer's point of view, VRM offers opportunities to engage with customers in far more rich and meaningful ways than is currently possible. Specifically, it opens new opportunities in five key areas:

- operational efficiency

- customer acquisition

- customer development

- customer retention

- continuous product and service improvement.

Let's look at each one of these in turn. 
Table 1: Some examples of VRM building blocks

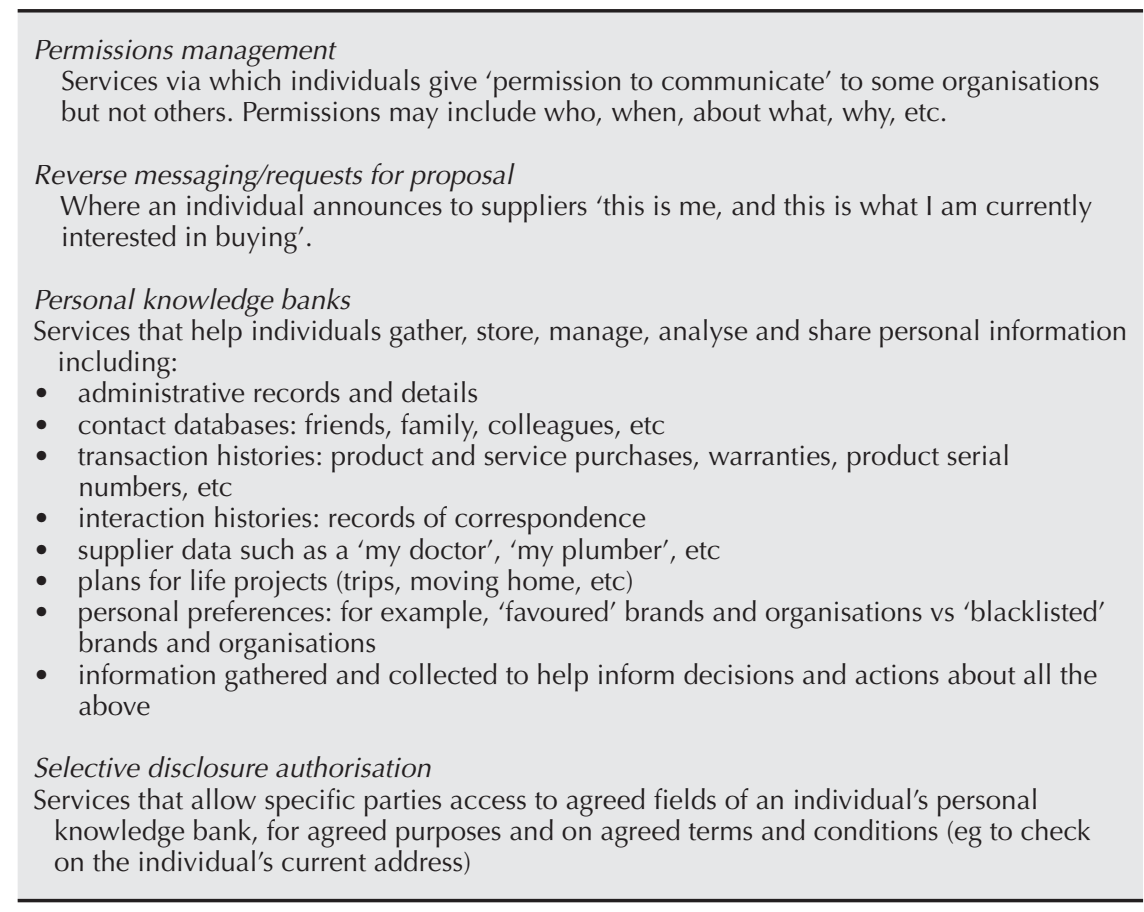

\section{With VRM individuals hold master data}

\section{Operational efficiency}

Corporate data managers face an uphill struggle in keeping their customer data up-to-date and accurate. In any one year, up to 15 per cent of their customers are likely to move house or die. A number of others are likely to get married and change their name. One of us moved to our current address 12 years ago; we are still getting a few mailings a week for the previous occupants. Today, data management (data cleansing, data enhancement, regulatory compliance, etc) swallows up significant proportions of most organisations' CRM costs.

With VRM, the customer becomes the holder of his own master data. VRM tools enable organisations to access these data (on terms agreed on with the customer) to check and update their own files. The Community Interest Company MyDex is currently piloting the technology infrastructure for such services.

With VRM, customers not only replicate vendor-side data, but also back it up and improve on it. They also possess means to organise a superset of data that, with the customer's permission, can be accessed to improve vendors' product development and offerings to market.

High-friction interactions, such as Terms of Service (ToS) agreements, which today customers almost never read and which impede the customer acquisition and retention process, can be eliminated, because the customer will come equipped with his or her own ToS, expressing goodwill, good credit, readiness to pay bills on time, and other essentially social agreements that are taken for granted when a person walks into a store, yet still require a team of solicitors' intervention when meeting and greeting is done online. 


\section{VRM helps individuals say "This is me; this is what I want"}

\section{Reverse messaging creates new win-wins between buyers and sellers}

\section{Customer acquisition}

The current approach to customer acquisition is based on guesswork. Marketers study the profiles of the people who already buy their products, looking at factors such as age, sex, income or other lifestyle attributes. They then create a model of what such a customer looks like, and acquire data about other people displaying similar characteristics. The trouble is, even with very sophisticated modelling drawing on lots of data, the chances of picking exactly the right offer at exactly the right time are very small. If the industry had cracked this problem, response rates to direct mail campaigns wouldn't lie in the 1-2 per cent region. They would be much, much higher.

VRM sidesteps all these problems by enabling individuals to present their desires and intentions to the marketplace: 'Here I am and right now, this is what I want to buy'. This may involve selective disclosure. For example, they may reveal that they have money ready to pay, that their credit is good, that they already belong to particular loyalty programmes and that they can provide the data necessary to complete transactions. They may decide not to reveal where they live and what their names are until a relationship is actually established.

This not only allows demand to find supply, and to achieve close to 100 per cent hit rates from both sides' perspective, but to initiate better relationships in the first place.

Reverse messaging can take many different forms. It may be 'I want to buy a Nikon D3 (an exact product) within the next couple of days (an exact time frame). What do you offer?' It may be 'I am planning to buy a camera some time over the next month or so. This is my price bracket, and these are the sorts of things I want to do with it. Please send me suggestions and offers'. Or it may be a much more specific 'request for proposal', providing detailed specifications of what the individual is looking for in his ideal product.

Some VRM models envisage individual customers communicating directly with selected suppliers with specific requests. Others pass the message through an intermediary (thereby, eg, protecting the individual's identity until he or she chooses to make a transaction). Sometimes the intermediary aggregates these signals of demand, thereby reducing vendors' costs when responding.

(Many models are on the table. What puts them in play now is a rapidly expanding abundance of software and hardware building materials. The portfolio of open source code, open standards, open APIs (application programming interfaces), open data models, open hardware designs (such as the PC has possessed from the beginning, and mobile phones are just beginning to embody) and open systems in general now number in the millions. Together these add immensely to what Oxford professor Jonathan Zittrain calls the 'generativity' of the Net and its most useful devices. VRM tools will largely be built from these generative components.)

Most customer demand-signalling mechanisms will have strict time controls: a window for communication is opened up for a specific period of time, via a bespoke URL, for example. Once it is closed, the

\section{Time sensitive communication}


channel of communication is also closed; sellers cannot use it as a data-gathering opportunity or an excuse for perpetual spamming.

The results are win-win, by design. Buyers get to present their demand in efficient and labour-saving ways, and in return get easy access to extremely relevant information at the right time, as well as precisely what they are looking for. Sellers know they are talking to 'hot' prospects, allowing those sellers to eliminate much of the waste inherent in essentially speculative marketing and selling processes. They can also concentrate resources on actual customers that are really tuned in to their products, services and brands.

Reverse messaging represents a particularly big opportunity for sellers in big ticket and/or complex products or services where there are long buyer lead times between initial consideration and final purchase decision (eg cars, moving house, home improvements, non-routine travel, etc). Marketers want to talk to these prospective customers during this decision-making process, but under the current set-up they have no means of identifying who these customers are. By giving individuals means for providing this information, VRM does more than open up new marketing opportunities. It opens up whole new markets based on actual demand and the ability to fulfil that demand in ways that can be constantly improved.

\section{Customer development}

Once a customer has purchased a product, some sort of relationship is created between the two sides. CRM promised to maximise the value of this relationship, yet few customers would be willing to call the relationship by that name at all. The reasons for this are as follows.

First, outdated industry attitudes (value extraction, customer data as an organisational asset) have led some organisations to abuse relationships rather than deepen them. Two obvious examples are selling personal data to third parties and spamming the customer with unwelcome selling messages.

Secondly, there are deep structural limitations to existing CRM

\section{Structural flows in direct marketing}

\section{The myth of the single customer view}

systems. The two most important ones are listed below.

(1) It is impossible for any single organisation to develop a genuine 'single customer view'. The view organisations have of their customers is constrained by the dealings they have with them. For example, a typical customer nowadays may have a dozen or more relationships with different financial services providers (current accounts, credit cards, loans, mortgages, savings, pensions, investments, life assurance, insurances, etc). Many financial services providers are still struggling to get internal data silos to talk to each other, never mind that these fail to transcend the vast gulf that lies between different organisations. As a result, every organisation's picture of its customers is partial (and often very distorted), leading to flawed models and mistaken predictions and therefore irrelevant messages. In reality, there is only one entity that can integrate all these data without hitting 
insurmountable privacy and data protection issues, and that is the individual himself. Only that individual is in a position to see his or her whole portfolio of relationships, correct errors and suggest relevant improvements. Surveys of customer populations are bad substitutes at best.

(2) Even if, by some miracle, an organisation is able to generate a single customer view, no sooner would it have achieved this feat than it would be out of date. Unless the individual is actively updating the data with changed circumstances, plans, priorities, preferences and so on, the value of the data quickly erodes. In addition, even with a genuine single customer view, the customer cannot inform the seller of what the individual's plans and intentions are, because these are still located in the consumer's head. ${ }^{1}$ Again, the result is large amounts of irrelevant messaging and therefore waste.

Take an example from a good direct marketing practitioner. Amazon regularly sends one of us e-mails along the lines of 'other people who bought MySQL for Dummies bought MySQL for Beginners'. The problem is that we bought the MySQL book for somebody else, and the chances of our buying anything else in this category are close to zero. The need has passed. Of course, Amazon could provide us with tools to flag that these offers were no longer relevant. But why should we spend our precious time cleaning up their data? (Especially considering that we have close to 150 such supplier relationships, not just one.)

\section{Why 'relationship building' often fails}

\section{Personal data stores}

This basic inability to understand and keep up to date with changing customer circumstances and preferences is why so many organisations' 'relationship building' exercises fail to achieve their objectives and are often downright counterproductive. If direct marketers had been able to overcome these structural flaws, they would not be facing the situation they face today, where often 50 per cent or more of their own customers have opted out of receiving communications from them. (You know you've got problems when your biggest, most immediate challenge is not 'what shall we say to our customers?' but 'how can we stop them shutting the door in our face?')

VRM tackles these problems by providing the customer with ways to manage vendor relationships. Emerging VRM tools enable customers to specify when they wish to be communicated with, via what channels, and about what topics. As with reverse messaging, giving customers the ability to specify the terms of engagement generates a powerful win-win: increased relevance and reduced hassle for the customer and increased returns and reduced waste for the organisation.

But that's just the beginning. One of the foundation stones of VRM is the individual's increased ability to build their own personal databases, including their own transaction histories, product and supplier preferences and so on. As these personal databases grow (in market penetration, richness and scale) organisations will seek access to pre-specified fields - on a permission-only basis of course - to 
update their records, to make recommendations about 'your next best purchase', to identify areas where the customer is not getting best value from the organisation (avoiding risks to customer retention), to identify areas where the customer is not getting best value from other organisations (thereby opening up opportunities for customer acquisition and business growth), and simply to gain deeper insights into customer trends, changing priorities and preferences.

Organisations will use this information to align their communications and services far more tightly to customers' actual preferences, thereby leading to greater value for both sides. The critical shift here is that the supplier is now a guest in the customer's house: he is only allowed entry if he keeps to the customer's rules and offers the customer a clear benefit in return. The win-win is generated from deeper, richer and more frequent information exchanges that are useful for both parties and for vendors' partners farther back up the supply chain.

\section{Customer retention}

It goes without saying that if an organisation offers its customers superior value they have no reason to look elsewhere. This was the original vision behind CRM as envisaged by early pioneers such as Don Peppers and Martha Rogers in their books about 'one-to-one marketing'. Under this vision, an organisation's relationship with its customers provides it with one crucial competitive advantage that its rivals can never access: the customer information that the relationship reveals. This information allows the organisation to tightly target every aspect of its marketing, from new product development through communication to pricing, in ways that generate superior customer value at lower cost (lower cost because better targeting means less waste), thereby triggering a virtuous spiral of increased customer retention, leading to better organisation economics and enabling the organisation to invest even more in enriching the relationship.

We can now see why this vision failed to materialise. While the core idea was good, it assumed that the first 'one' in 'one-to-one' was the organisation. ${ }^{2}$ This was an understandable mistake, because the net and the web were still young, and sellers were scaffolding their understanding of relationships with the asymmetrical one-to-many concepts that served well in the pre-net retail environment. In that environment, the means to achieve genuine data sharing between customer and organisation did not exist. Just as it takes two to tango, it also takes two to create a relationship. CRM therefore became a onesided attempt at relationship building where the organisation did everything and the customer nothing - except sit there as a 'target', whether he or she liked it or not. That's why, like the sound of one hand clapping, CRM did not make a huge noise for customers.

By providing customers with both the technical means to share

\section{VRM gives customers} control information and the reassurance of control over content and process, VRM actually makes the original vision of CRM possible.

At a more practical and operational level, VRM-enabled services also help organisations to be more proactive in dealing with likely 
VRM enables improved seller alignment defections. For example, the home moving planning service MoveMe. com is already earning customer retention lead fees from utility suppliers. It alerts them to the fact that one of their customers is planning to move home, thereby giving them the opportunity to communicate with customers to maintain uninterrupted service, rather than to go through the hassle of switching.

VRM may also eliminate the need for 'loyalty programmes' that are little more than forms of friction for all involved. Once there is a richer exchange of information between customer and supplier, organisations can deliver greater alignment of products, services and information to customers' expressed preferences. This is likely to create far more customer 'loyalty' than artificial points-based sales inducements.

\section{Continuous product and service improvement}

Most of the smartest people don't work for your organisation or for your competitors. The largest bulk of knowledge about any product is not inside any organisation's R\&D department, its management, its manufacturing, or its sales and marketing personnel. It's out in the marketplace, in the form of its customers.

Too often product improvement consists of surveying and guesswork. Yet we already know that customers are often in the best position to 'de-bug' products once they are released, and can also generate new product ideas.

Within the small community of early internet adopters, the term 'internet time' was used to label the rapid rate of change that became possible when any number of people could become involved in product development. One reason why open source development methods have been so successful is that anyone, anywhere with real help to contribute can participate in a form of 'barn raising'. VRM makes possible the same kind of rapid and efficient improvement in product development, distribution systems, and pricing systems and service offerings.

\section{Becoming VRM ready}

If we put all these elements together - improved operational efficiency plus improved customer acquisition, development and retention, and continuous product and service improvement - we see how rich the potential of VRM is. But how will it be implemented?

One essential building block is the development of new personal information management services offering personal data stores and related applications. When it comes to marketing communications, one example of an immediate VRM solution involves four components. These are as follows:

\section{(1) Cross-media suppression file}

The first and most fundamental element of the required hard re-set is giving consumers the opportunity to choose a blanket opt-out from all direct marketing: an across-the-board suppression file. This is a reference file within which individuals can register a preference to 


\section{Specific opt-ins}

\section{Specified messages}

receive NO direct marketing messages at all from point of registration onwards, unless they have actively and overtly opted in through a consents management vehicle under their control. This file would include all direct media (direct mail, e-mail, SMS, telephone, mobile telephone, VOIP, pop-ups/that is, tracking cookies, and any other direct media invented over time). The file would be created as a stand-alone entity, but could be configured to take in feeds from existing suppression files such as Mailing Preference Service, Do Not Call, the proposed Do Not Track, etc.

\section{(2) Persona/role-based opt-in capability}

The second element is a capability for the individual to establish one or more 'privacy profiles' at persona/role level. The ability to operate at persona level is important because most individuals are managing many different 'lives' all at the same time, and each 'life' requires different communications preferences. For example, in their head of household mode individuals may wish to receive 'no junk mail', but in their 'Secretary of the Golf Club' persona they may be happy to receive messages from useful business services only — but delivered to a different address.

\section{(3) Articulation of needs/wants (intentions) in usable format}

Once the blanket opt-out is established as a point of principle, the end user must be enabled to opt back in to specific communications on their own terms. This means being able to specify some or all of the following:

- who they wish to receive messages from

- which message types they wish to receive (eg offers, quotations, reminders, news updates)

- about what they wish to hear

- at what time they wish messages to arrive

- through which channel

- over which time period the messaging should be switched on.

\section{(4) Message management capability}

Lastly, we need a message matching and management capability. The above capabilities, in combination, generate a file of 'opted in, buying intentions requesting matching offers'. This must then be matched against a file of 'people/organisations that want to sell stuff or provide requested offers or information'. Where a match is found, an introduction is made. Where one is not, no message is sent (or a message is sent stating that no messages matching the criteria set are available).

Ideally, this message matching and management capability will be able to work across all relevant media. It should also have 'closed-loop' reporting capabilities so that all parties can track the success of their actions and learn for future use. It should help the recipient understand the upsides and downsides of the various media options in the context 


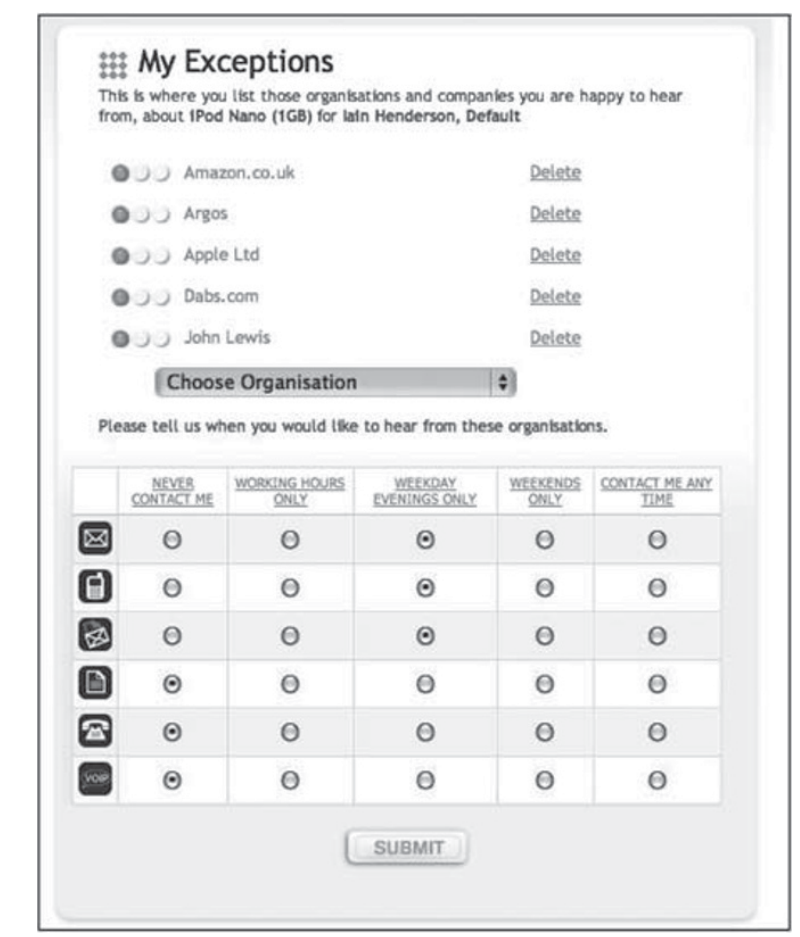

Figure 1: A prototype of customer-managed supplier communication management system from the Privacy Preference Service

of what they wish to receive so that they can choose which works best for each message. (For example, a mailed catalogue may be the most environmentally damaging, but it may still be the best means of deciding which conservatory to buy as it offers the most detailed visuals and descriptions in a format that can be browsed in a relaxed and unpressured manner.)

The above four components are not just pie-in-the-sky theory. Proofof-concept prototypes have already been built (see www.

privacypreferenceservice.com/hdy45 for example). Many more applications and services are being developed under the auspices and encouragement of Harvard Law School-backed Project VRM (http:// cyber.law.harvard.edu/projectvrm/Main_Page) (Figure 1).

VRM is here to stay

\section{Conclusion}

VRM is going to happen whether direct marketers like it or not. The business opportunities inherent in providing customers with tools and services that help them collect, store and manage their own personal data better - and in using these data to manage relationships with suppliers - are too great to be ignored, especially when they represent new revenue streams for industry 'outsiders' such as internet entrepreneurs and software organisations. These tools are going to be provided by a variety of organisations, and through allied development in a variety of open source communities. The potential value for customers - from reduced hassle through to greatly improved value 


\section{VRM helps direct marketing transcend its limitations}

\section{VRM creates a new win-win between buyers and sellers}

- means that there will be significant demand for these services. Organisations that are not invited into customer-managed relationships will be left out in the cold.

Over recent decades the direct marketing industry has been painting itself into a corner. Many new saviours have promised to build bridges out of that corner, including CRM, data mining, new lower cost direct channels such as mobile, Google Adwords or Facebook, and supercharged data mining such as behavioural tracking/targeting. They never deliver their claimed potential, all for the same reason: they still treat the customer as a 'target' who is kept out of the driver's seat and derives no real value from a process that is not theirs to drive.

On its own, direct marketing cannot transcend its historical, in-built limitations. Its legacy assumptions and structures were built in another time for a place that no longer exists. It needs help from the outside: from its customers. VRM makes this possible.

At first glance, VRM seems to contradict many of the things direct marketers see as 'secrets of success': customer data as a corporate asset, predictability and control. Yet on closer inspection, it actually offers us the opportunity to achieve what we have always wanted to achieve: greater relevance, lower costs and improved ROI based on closer, richer win-win relationships with customers.

VRM is not going to change the face of the industry overnight, but it $i s$ going to change how the industry works. Given the scale of change it heralds - to legacy systems, processes, vested interests, attitudes, skills and habits - organisations need to start preparing now. Is your organisation VRM aware and VRM ready?

\section{References}

1. Many direct marketers like to boast that they know what their customers are going to do next, before their customers do. Mostly, these boasts are just hot air. Even where they do have substance, the substance only holds true if kept at an aggregated statistical level: for example, 'over the next six months, 5 per cent of customers with this product will choose to upgrade to that'. However, the more you try to apply this to the next actions of particular individuals, the worse your ability to make accurate predictions. That is why, operationally speaking, the boast leads us nowhere.

2. Mitchell, A. (2000) 'In one-to-one marketing which "one" comes first?' Interactive Marketing, Vol. 1, No. 4, pp. 254-367. 